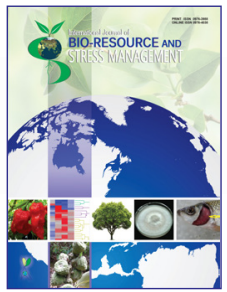

\title{
Use of Aloe Vera Gel Coating as Preservative on Tomato
}

\author{
Ambuza Roy ${ }^{1}$ and Anindita Karmakar ${ }^{2 *}$
}

Dept. of Post Harvest Engineering Faculty of Agricultural Engineering, Bidhan Chandra Krishi Viswavidyalaya, Mohanpur, Nadia, West Bengal (741 252), India

\begin{tabular}{l}
\hline Open Access \\
Corresponding Author \\
\hline Anindita Karmakar \\
e-mail: karmakar.ani@gmail.com \\
Citation: Roy and Karmakar, 2019. Use of Aloe Vera \\
Gel Coating as Preservative on Tomato. International \\
Journal of Bio-resource and Stress Management \\
2019, 10(5):461-466. HTTPS://DOI.ORG/10.23910/ \\
IJBSM/2019.10.5.2019
\end{tabular}

Copyright: (c) 2019 Roy and Karmakar. This is an open access article that permits unrestricted use, distribution and reproduction in any medium after the author(s) and source are credited.

Data Availability Statement: Legal restrictions are imposed on the public sharing of raw data. However, authors have full right to transfer or share the data in raw form upon request subject to either meeting the conditions of the original consents and the original research study. Further, access of data needs to meet whether the user complies with the ethical and legal obligations as data controllers to allow for secondary use of the data outside of the original study.

Conflict of interests: The authors have declared that no conflict of interest exists.

\begin{abstract}
Tomato is highly demanded in the market because of its high nutritional value. But Tomato has a very short shelf life due to its perishable nature. Short shelf life coupled with improper processing facilities results in heavy socio-economic loss. Aloe vera gel mainly composed of polysaccharides has been recently explored as an effective edible coating to increase the shelf life of fruits and vegetables because of its antifungal and antimicrobial activity. Hence, the present study was conducted to evaluate the effect of aloe vera coating on shelf life of tomato. Tomatoes were washed, surface water was removed and then coated with aloe vera gel. After coating fruit surface was air dried and kept at refrigerated condition $\left(5 \pm 1{ }^{\circ} \mathrm{C}, 90-95 \% \mathrm{RH}\right)$. The various physicochemical properties like moisture content, physiological loss in weight, total soluble solid content, ascorbic acid content, colour and firmness were measured at a regular interval for both uncoated and coated tomatoes for a storage period of 21 days. Aloe vera gel coated tomatoes were found to maintain their moisture, colour and firmness better than the uncoated ones. They also showed lesser reduction in physiological weight loss, ascorbic acid content and total soluble solid content. The uncoated tomatoes showed rapid deterioration and almost $90 \%$ of tomatoes were decayed after 21 days of storage whereas aloe vera coated tomatoes showed no deterioration within this period and only $10 \%$ of the coated tomatoes were decayed after 28 days of storage.
\end{abstract}

Keywords: Aloe vera, edible coating, shelf life, preservative, tomatoes

\section{Introduction}

Post harvest losses of fruits and vegetables in India are approximately $35-40 \%$ which is a matter of grave concern for Indian agriculture sector (Krishijagran.com, 2019). India is the second-largest producer of fruits and vegetables, after China. But the post harvest losses that occur during different post-harvest processes till the product reach to the consumer directly affect all the producers, supplier and consumers in the marketing chain. These losses occur mainly due to the lack of proper harvest practices, transportation and cold storage facilities. Several techniques such as refrigeration, controlled atmosphere storage, modified atmosphere storage, chemical preservatives and packaging are being used for post harvest quality retention of different fruits and vegetables (Almenar et al., 2006; Venkateswarlu et al., 2016; Khan et al., 2015). But most of them are costly and pose health and environmental problems (Prasad et al., 2018).

\section{Article History}

RECEIVED in $03^{\text {rd }}$ August 2019 RECEIVED in revised form $01^{\text {st }}$ October 2019 ACCEPTED in final form $07^{\text {th }}$ October 2019 
Application of edible coating on fruits and vegetables is a healthy and eco friendly post harvest treatment which is very demanding now-a-days. The edible films and coating are the primary packaging which is prepared from edible materials (Melvin and Shin, 2012). The edible coating around the fruits reduces respiration, improves textural quality, retains volatile flavour compounds and reduces microbial growth (Mahfoudi et al., 2014). Edible coating affectively influences different physical, physiological, biochemical and pathological factors to enhance the post harvest shelf life (Prasad et al., 2018). Edible coating can provide the same effect as modified atmosphere storage in modifying internal gas composition (Park et al., 1994). Edible coatings have high potential to control browning, discolour activity, off flavour, microbial activity (Dhall, 2013). Apart from these advantages different food grade additives can also be added to the coating material to improve their composition which in turn improves the quality of the fruits and vegetables.

Edible coatings may be composed of polysaccharides, proteins, lipids and their combination. Considering the increasing demands of consumers for natural fresh like fruits, attention is being paid to use natural materials as edible coating. In this direction, recently there has been an increasing interest to use aloe vera gel as edible coating. Aloe vera gel is the mucilaginous gel obtained from the squeezing of the clear jelly-like substance of the parenchyma tissue of Aloe vera leaves. Aloe vera gel has antifungal, antimicrobial and anti-inflammatory properties (Misir et al., 2014). Aloe vera along with increasing the post harvest shelf life of product maintains the sensory properties of the product. A study conducted by Benitez et al. (2015) by application of three different types of edible coatings such as aloe vera, chitosan and sodium alginate reported that aloe vera was the most effective one to both extend the postharvest shelf life and maintain the sensory_properties of the product through the storage period of 12 days at $4 \pm 1^{\circ} \mathrm{C}$. Aloe vera gel-based edible coating was also reported to prevent loss of moisture, colour, titrable acidity, $\mathrm{pH}$ and firmness, control respiratory rate and maturation development and reduce microorganism proliferation on different fruits like sweet cherries, mangoes, grapes, eggplants etc. (Martinez et al., 2006; Sophia et al., 2015; Ali et al., 2016; Amanullah et al., 2016).

Tomato (Solanum copersicum) is one of the most important vegetable crops in India. Tomato contains different bioactive phytochemicals along with carotenoids, vitamin C, and the phenolic compounds which make them an excellent source of nutrition. Tomato is grown in an area of 0.8 million hectares with an average annual production of 20.7 million tonnes in India during 2016-17 (NHB, 2017). After harvest the main factors that influence the shelf life of tomato include improper handling, high humidity, high temperature and Ethylene exposure (Dang et al., 2008). Also physicochemical profile of tomato fruits changes significantly over time and with the storage temperature (Okolie and Sanni, 2012). These changes result in loss of quality and restrict its own natural shelf life. Therefore this research work was undertaken to increase the shelf life of tomato by aloe vera coating and to evaluate the effect of coating on physicochemical properties during storage.

\section{Materials and Methods}

An experiment was carried out in the Food Engineering Department of Bidhan Chandra Krishi Viswavidyalaya, India during 2018. Freshly harvested tomato fruits were collected from a local market. Before coating, tomato fruits were washed with water to remove dust and dirt. The coating solution used for tomato fruits was Health viva aloe vera juice containing $95 \%$ aloe vera juice and rest $5 \%$ of stabilizer, acidity regulator and preservatives with no added artificial colour and flavour. Uncoated samples were used as control. Coating of tomato was done by dipping them in the coating solution for five minutes. Tomatoes were then dried at room temperature to allow a thin film layer to be formed on the fruits. Both the coated and uncoated samples were then stored in the refrigerator at a temperature of $5 \pm 1^{\circ} \mathrm{C}$ and 90 $95 \%$ relative humidity. Various physicochemical properties were determined at 7 days interval for 28 days. The coating was done according to the flow diagram presented in Figure 1.

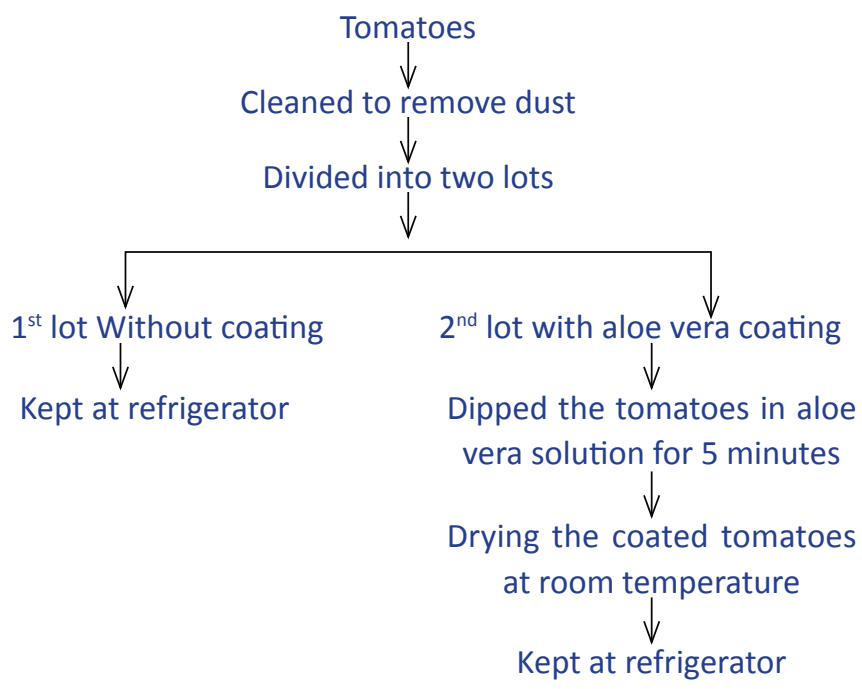

Figure 1: Flow diagram for coating of tomatoes

\subsection{Physicochemical analysis}

Weight losses were determined using analytical weighing balance. Moisture content was determined by hot air oven. Surface colour was measured using a Hunter Lab colorimeter. The data obtained in terms of $L^{*}, a^{*}$ and $b^{*}$ were converted into hue angle and chroma, which provided information about the colour index (colour intensity) of fruit samples. The colour difference was calculated to evaluate the difference in colour between the tested sample and reference material or fresh sample. The following equations were used to calculate the surface colour analysis.

$\Delta \mathrm{E}=\mathrm{V}\left[\left(\Delta \mathrm{L}^{*}\right)^{2}+\left(\Delta \mathrm{a}^{*}\right)^{2}+\left(\Delta \mathrm{b}^{*}\right)^{2}\right]$ 
$h^{0}=\tan ^{-1}\left(b^{*} / a^{*}\right)$

Firmness was measured as the maximum force $(\mathrm{N})$ required for the deformation or breakage of tissues of the tomatoes. Firmness was measured by a compression test with a texture analyzer (TAXT Plus Texture Analyzer, Stable Microsystem, UK) using a stainless steel cylindrical probe $(P / 75)$ with 60 mm diameter.

Total soluble solids were determined by using a digital refractometer from freshly extracted juice of tomato of each treatment. Vitamin $\mathrm{C}$ content of the samples was measured using 2, 6-dichlorophenol indophenol method as described by AOAC (2000).

The psychological decay of tomatoes was inspected visually at the end of the storage, evaluating the skin dehydration level of the products. Tomato fruits showing surface mycelial development were considered decayed. The results were expressed as percentage of damaged products.

The numbers of decaying fruits were counted on each $7^{\text {th }}$ day of storage and calculated using the formula,

Decay percentage $=$ (number of fruits decayed/ total number of fruits) $\times 100 \%$; (Kator et al., 2018).

\section{Results and Discussion}

\subsection{Physiological loss in weight}

Percentage loss in weight was found to increase in all the treatments for both the coated and uncoated tomatoes as the storage period progressed (Figure 2). The physiological loss in weight was more in case of the uncoated samples than the aloe vera coated samples. Mainly rate of respiration and moisture evaporation control the phenomenon of weight loss. The reduction in weight loss in coated samples was probably due to the effects of the coatings which act as a semi permeable barrier against movement of oxygen,

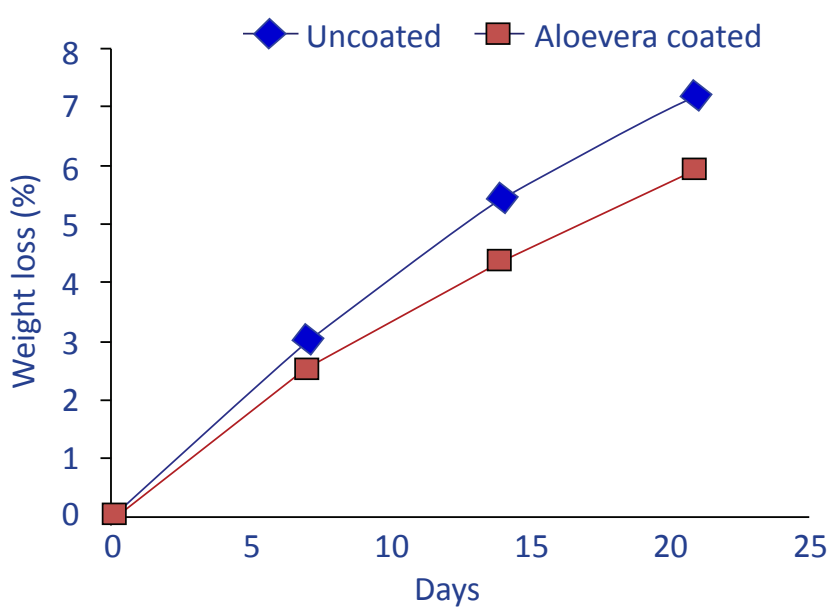

Figure 2: Percentage of weight loss during storage period

carbon dioxide, moisture and solute. The percentage losses of moisture after 21 days of storage for uncoated and coated tomatoes were $7.18 \%$ and $5.95 \%$ respectively. Similar result was obtained by Atlaw (2018) where the weight loss for uncoated mangoes and aloe vera coated mangoes stored in a temperature of $31^{\circ} \mathrm{C}$ were $22.04 \%$ and $8.6 \%$ after 35 days of storage.

\subsection{Moisture content}

The data on moisture content for coated and uncoated samples are presented in Figure 3. Moisture contents of uncoated tomato samples have decreased more rapidly in comparison to the coated samples. So the uncoated tomato samples started to shrink after seven days of storage period whereas the treated samples have remained fresh even after twenty days of refrigeration. Initial moisture content of the tomatoes was recorded as $96.25 \%$. On the $21^{\text {st }}$ day, moisture contents for uncoated and aloe vera coated samples were $89.64 \%$ and $93.73 \%$ respectively. On the $21^{\text {st }}$ day, the loss in moisture content for the uncoated samples and for the aloe vera coated samples were $6.86 \%$ and $2.61 \%$ respectively. Hence we can say that the aloe vera coating has a positive effect on the change in the loss of moisture content of tomato.

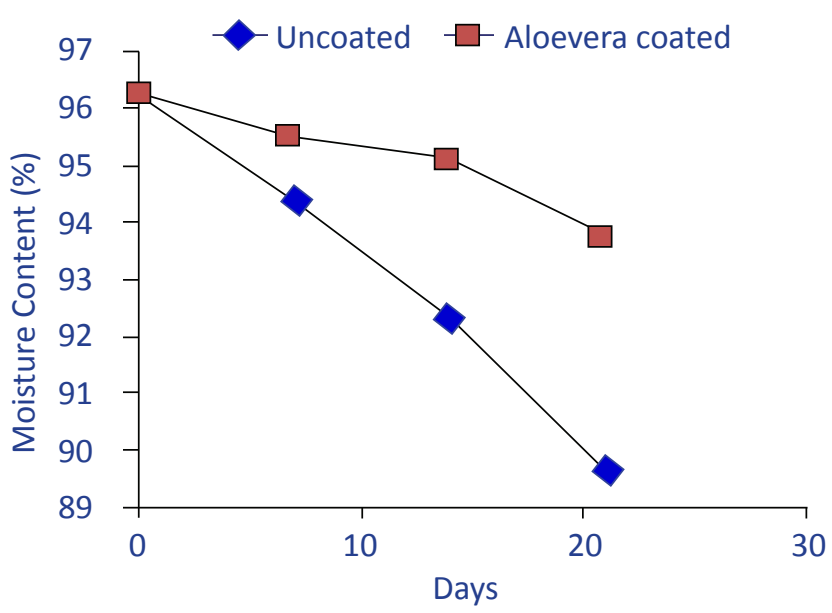

Figure 3: Moisture content of tomatoes during storage period

\subsection{Ascorbic acid content}

Ascorbic acid is one of the most important nutritional value parameters in tomatoes. Hence, changes in ascorbic acid in tomatoes during storage have been monitored to investigate the level of effects of edible coating treatments. Figure 4 shows the ascorbic acid content of coated and uncoated tomato samples that had significant variation during the 21 days of storage under refrigerated conditions. The value of ascorbic acid content in this study on the 1st day was 22.14 $\mathrm{mg} 100 \mathrm{~g}^{-1}$ for the uncoated samples. At the end of the storage period, the ascorbic acid content of coated tomatoes was found to be higher than the uncoated tomatoes. The ascorbic acid content on the $21^{\text {st }}$ day of uncoated and aloe vera coated tomatoes were found to be $14.08 \mathrm{mg} / 100 \mathrm{~g}^{-1}$ and $17.46 \mathrm{mg} / 100 \mathrm{~g} \mathrm{~g}^{-1}$ respectively. The higher ascorbic acid content of coated tomatoes near the end of the storage period could be due to the fact that coating served as a protective layer against the auto oxidation of fruit by 


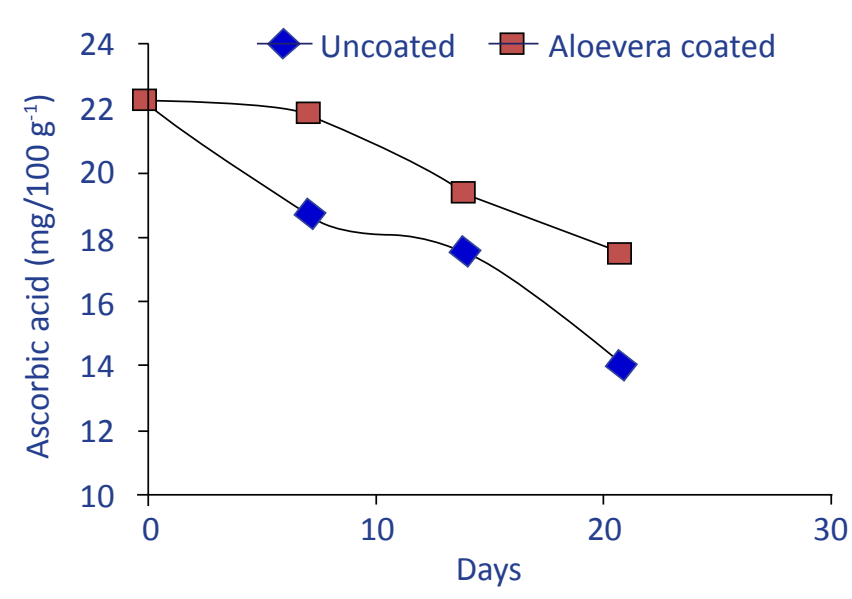

Figure 4: Ascorbic acid present in tomatoes during storage

controlling the permeability of $\mathrm{O}_{2}$ and $\mathrm{CO}_{2}$ deep inside the fruit. Mani et al. (2017) also reported similar findings where the use of edible coatings significantly reduced the loss of vitamin $\mathrm{C}$ in ber fruit.

\subsection{Total soluble solid content}

Observations during storage revealed that the TSS content of both coated and uncoated tomatoes increased up to a certain limit and thereafter it decreased as the storage period progressed (Figure 5). The rate of increase and decrease of TSS for coated tomatoes were less compared to the uncoated

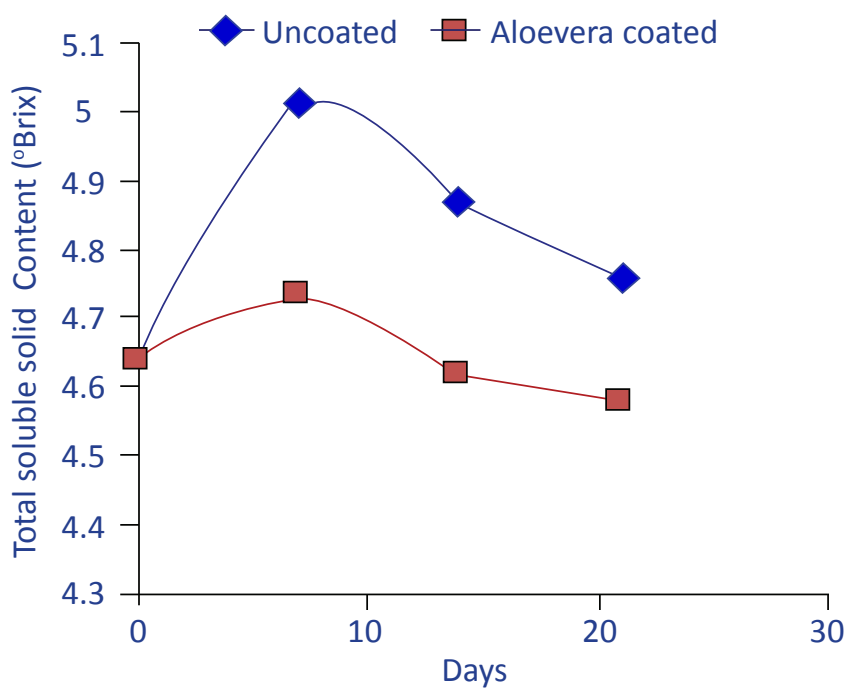

Figure 5: Total Soluble Solid present in tomatoes during storage

ones. Highest TSS content was observed in uncoated fruits at the $7^{\text {th }}$ day of storage. Coated tomatoes showed a lower increase in soluble solid content. Kanmani et al. (2017) also reported that the TSS concentration slightly increased initially and latter decreased in case of tomatoes coated with CMC / pectin. The breakage of carbohydrates and pectin, partial hydrolysis of protein and decomposition of glycosides into subunits during respiration lead to a decrease of total soluble solids during storage. Garcia et al. (2014) also reported that samples coated with pure extract of aloe vera showed a lower increase in soluble solid content than the uncoated ones. This may be due to the fact that the presence of coating slows down the rate of hydrolysis of carbohydrates which restricts the rise of total soluble solid content.

\subsection{Firmness}

Figure 6 shows the firmness of the coated and uncoated tomatoes during the entire storage period. The hardness showed a decline from $28.8 \mathrm{~N}$ at 0 day to $22.9 \mathrm{~N}$ and $25.7 \mathrm{~N}$ for the uncoated and coated tomatoes at $21^{\text {st }}$ day respectively. This means that the uncoated fruit samples showed a poor hardness at $21^{\text {st }}$ day of storage as compared to the coated

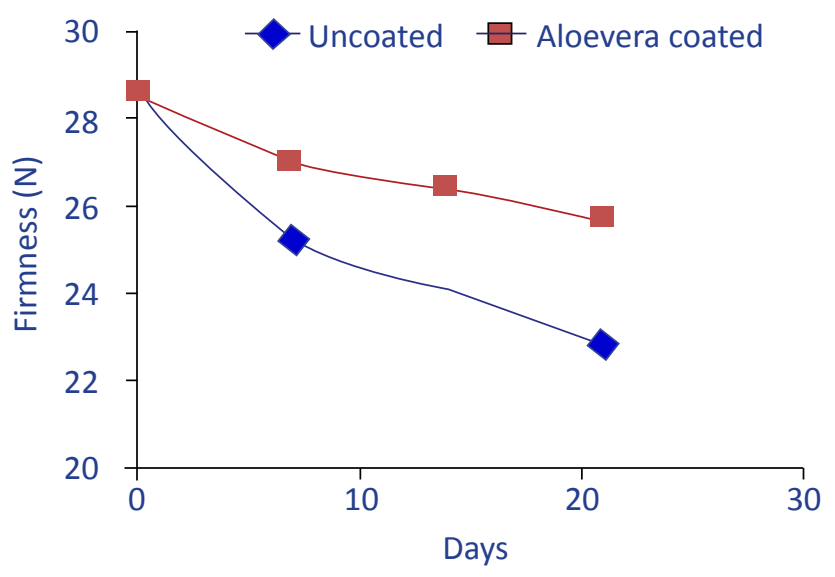

Figure 6: Firmness of Tomatoes during storage period

ones. Mani et al. (2017) reported the similar findings in case of ber fruit for 15 days of storage. They also concluded that the higher hardness of the coated fruits may be due to the fact that as respiration rate is reduced also reduced is the degradation of water insoluble calcium pectate (Ca-pectate) or calcium bridge that renders strength to the fruit skin. According to Keneko et al. (2002) coating was the most effective treatment for retardation of softening of harvested fruits and vegetables compared to the uncoated ones.

\subsection{Colour}

Colour is an important quality attribute for marketing of products as it is usually the first characteristic noted by potential consumers. Moreover colour acts as an indicator of the level of natural deterioration of fresh foods. Tomatoes, both control and coated, registered some changes in $L^{*}, a^{*}$ and $b^{*}$ values during the storage period. Table 1 shows the change in colour of the coated and uncoated fruits and hue angle. However, the changes were less for the tomatoes treated with aloevera in comparison to the uncoated ones. The colour change values after 21 days of storage were 9.90 and 11.6 for coated and uncoated tomatoes. Hue angle were $28.39^{\circ}$ and $25.91^{\circ}$ respectively. Misir et al. (2014) also got the similar type of result where aloevera gel treatment delayed the green colour loss on the fruit skin of apples stored at $2^{\circ} \mathrm{C}$ for 6 months.

\subsection{Ash content}

Ash content was evaluated for both the coated and uncoated 


\begin{tabular}{|c|c|c|c|c|c|c|c|c|c|c|}
\hline \multirow[t]{2}{*}{ Days } & \multicolumn{5}{|c|}{ Uncoated } & \multicolumn{5}{|c|}{ Coated } \\
\hline & $L^{*}$ & $a^{*}$ & $b^{*}$ & Hue angle & Colour change & $L^{*}$ & a* & $b^{*}$ & Hue angle & Colour change \\
\hline 0 & 35.49 & 35.41 & 28.42 & 38.750 & 0 & 35.46 & 35.44 & 28.52 & 38.830 & 0 \\
\hline 7 & 32.51 & 38.39 & 25.58 & 33.680 & 5.08 & 33.53 & 37.62 & 25.81 & 34.450 & 3.98 \\
\hline 14 & 31.79 & 41.82 & 23.75 & 29.590 & 6.78 & 32.49 & 39.54 & 23.63 & 30.860 & 7.04 \\
\hline 21 & 30.74 & 43.31 & 21.04 & 25.910 & 11.6 & 31.38 & 41.76 & 22.57 & 28.39o & 9.99 \\
\hline
\end{tabular}

tomatoes during the entire storage period. It was observed that ash content for all the samples showed gradual decrease during the storage period (Figure 7). Garcia et al. (2014) also found that the fresh and dehydrated tomato samples showed a marked decrease in ash content over the period of storage. This could probably due to the decrease of the salt content of the sample.

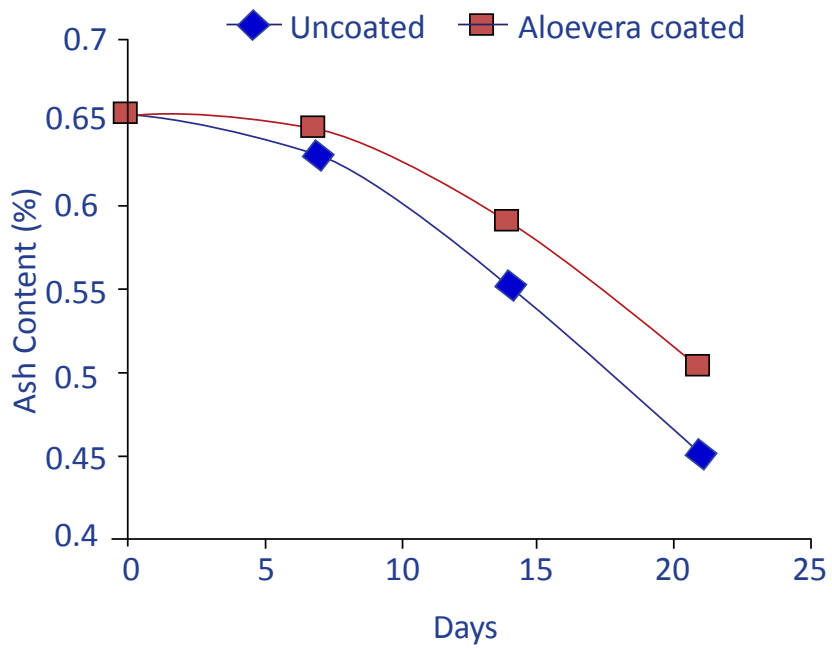

Figure 7: Percentage of ash content of tomato during storage

\subsection{Decay Percentage}

Table 2 clearly depicts that the uncoated tomatoes showed no signs of deterioration upto $14^{\text {th }}$ day of storage. But $90 \%$ of the uncoated tomatoes were decayed after 21 days of storage whereas aloe vera coated tomatoes showed only $10 \%$ of decay after 28 days of storage. Krishnan et al. (2017) reported that the shelf life of guava was increased by one week with the application of aloe vera coating under normal room temperature and shelf life could be extended upto one month under refrigerated condition.

\begin{tabular}{lcc}
\hline \multicolumn{3}{c}{ Table 2: Decay percentage (\%) of tomato during storage } \\
\hline Days & Decay Percentage (\%) uncoated & Aloevera coated \\
\hline 0 & 0 & 0 \\
7 & 0 & 0 \\
14 & 0 & 0 \\
21 & 90 & 0 \\
28 & 100 & 10 \\
\hline
\end{tabular}

\section{Conclusion}

The aloe vera gel coating significantly increased the shelf life of tomato by retention of moisture, colour and ascorbic acid. Aloe vera gel coated tomatoes also showed lesser percentage of loss in physiological weight and slower rate of total soluble solids development. The decay percentage of uncoated tomatoes was quite high in comparison to the coated ones. Hence, it can be concluded that aloe vera gel can act as a suitable bio preservative to enhance the shelf life of tomatoes.

\section{References}

Ali, J., Pandey, S., Singh V., Joshi P., 2016. Effect of Coating of Aloe Vera Gel on Shelf Life of Grapes. Current Research in Nutrition and Food Science 4(1), 58-68.

Almenar, E., Munoz, P.H., Lagaron, J. M., Catala, R., Gavara, R., 2006. Controlled atmosphere Storage of Wild Strawberry Fruit (Fragaria vesca L.). Journal of Agricultural and food Chemistry 54(1), 86-91.

Amanullah, S., Jahangir, M.M., Ikram, R.M., Sajid, M., Abbas, F., Mallano, A.I., 2016. Aloe vera coating efficiency on Shelf Life of Eggplants at Differential Storage Temperatures. Journal of Northeast Agricultural University (English Edition) 23(4), 15-25.

AOAC, 2000. Official methods of Analysis. Association of official Analytical chemists. 1111 North 19th street, Suite 20, $17^{\text {th }}$ Edi. Arlington, Virginia, USA. 22209.

Atlaw, T.K., 2018. Preparation and natural aloe Vera to enhance quality of Mango fruit. Journal of Food and Nutrition Sciences 6(3), 76-81.

Benitez, S., Achaerandio, I., Pujola, M., Sepulcre, F., 2015.Aloe vera as an alternative to traditional edible coatings used in fresh-cut fruits: A case of study with kiwifruit slices. LWT-Food Science and Technology 61(1), 184-193.

Dang, K.T., Singh, Z., Swinny, E.E., 2008. Edible coatings influence fruit ripening, quality, and aroma biosynthesis in mango fruit. Journal of Agricultural and Food Chemistry 56(4), 1361-1370.

Dhall, R.K., 2013. Advance in edible coating for fresh fruits and vegetables: A review. Critical Reviews in Food Science and Nutrition 53(5), 435-450.

Garcia, M.A., Casariego, A., Diaz, R., Roblejo, L., 2014. Effect of edible chitosan/zeolite coating on tomatoes quality during refrigerated storage. Emirates Journal of Food and Agriculture 26(3), 238-246. 
https://krishijagran.com/reducing-post-harvest-losses-in-fv/ Kanmani, V.M., Sashidevi, G., 2017. Application of biodegradable Aloe vera gel for extending the shelf-life of tomato. Food Science Research Journal 8(2), 132-137.

Kator, L., Iheanacho, A. C., Kortse,P., Aloho, K.P., 2018. Effect of organic preservatives on postharvest shelf life and quality of tomato fruits during storage. Asian Journal of Rresearch in Crop Science 2(1), 1-34.

Keneko, T., Claybon, R., Barringer, S.A., 2002. Consumer acceptability of color in processed tomato products by African, American, Latino and prototypical consumers. Journal of Food Quality 25, 487-498.

Khan, P., Mehraj, H., Taufique, T., Shiam, I.H., Jamal uddin, A.F.M., 2015. Chemical Preservatives for Increasing the shelf life of Gerbera. Journal of Bioscience and Agriculture Research 5(1), 30-36.

Krishnan, A.S., Ullas, A., Sagarika, N., Oommen, T.E., Sunaila, K., 2017. Development of Aloevera Based Edible Coating. International. Journal of Pure and Applied Biosciences 5(5), 796-801.

Mahfoudhi, N., Chouaibi, M., Hamdi, S., 2014. Effectiveness of almond gum trees exudates as a novel edible coating for improving post harvest quality of tomato (Solanum lycopersicum L.). Fruit Science Technology International 20(1), 33-43.

Mani, A., Jain, N., Singh, A.K., Sinha, M., 2017. Effects of aloevera edible coating on quality and postharvest physiology of Ber (Zizyphus mauritiana Lamk.) under ambient storage conditions. International. Journal of Pure and Applied Biosciences 5(6), 43-53.

Martinez, R.D., Alburquerque, N., Valverde, J., Guillen, F., Castillo, S., Valero, D., Serrano, M., 2006. Postharvest sweet cherry quality and safety maintenance by Aloe vera treatment: A new edible coating. Postharvest Biology and Technology 39(1), 93-100.

Melvin, A.P., Shin, J.L., 2012. The application of edible polymeric films and coatings in the food industry. Journal of Food Processing and Technology 4(2), 1-2.

Misir, J., Brishti, F., Hoque, Md., 2014. Aloevera gel as a noble edible coating for fresh fruits: A review. American Journal of food Science and Technology, 39, 93-100.

NHB, Horticultural Information Service, National Horticultural Board, Ministry of Agriculture, New Delhi, 2017. http:// nhb.gov.in/statistics/Publication/Horticulture.

Okolie, N.P., Sanni, T.E., 2012. Effect of post harvest treatments on quality of whole tomatoes. African Journal of Food Science 6(3), 70-76.

Park, H.J., Chinnan, M.S., Shewfelt, R.L., 1994. Edible cornzein film coatings to extend storage life of tomatoes. Journal of Food Processing and Preservation 18, 317-331.

Prasad, K., Guarav, A.K., Preethi, P., Pallavi, N., 2018. Edible coating technology for extending market life of horticultural produce. Acta Scientific Agriculture 2(5), 55-64.

Sophia, O., Robert, M., Ngwela, W.J., 2015. Effects of Aloe vera gel coatings and storage temperature on quality of mango (Mangifera indica L.) fruits. Annals of Biological Research 6(5), 1-6.

Venkateswarlu, A., Satyanarayana, C.V.V., Madhava, M., Sandhya, M., 2016. Studies on Modified Atmosphere packaging of Sapota. International Journal of Agriculture Sciences 54(8), 2862-2865. 